DOI: 10.12731/2658-6649-2019-11-3-85-102

УДК 579.873.21:579.252.55:615.281

\title{
СОЦИАЛЬНО-ПСИХОЛОГИЧЕСКИЕ ОСОБЕННОСТИ ПАЦИЕНТОВ С МНОЖЕСТВЕННОЙ ЛЕКАРСТВЕННОЙ УСТОЙЧИВОСТЬЮ MYCOBACTERIUM TUBERCULOSIS (CPABНЕНИЕ С РАНДОМИЗИРОВАННОЙ ВЫБОРКОЙ ЗДОРОВЫХ МУЖЧИН)
}

\author{
Чубарян В.Т., Саенко Г.И., Худоногов И.Ю., Модебадзе Е.В.
}

Актуальность. Исследования клинической эффективности различных медииинских технологий, применяемых при возникновении множественной лекарственной устойчивости (МЛУ) mycobacterium tuberculosis (МБТ), в последние десятилетия проводятся достаточно часто. Однако в значительной степени они сосредоточены на безопасности новых режимов лечения, на молекулярно-генетических методах диагностики, на разработке технологических платформ для создания инноваџионных противотуберкулёзных препаратов и т.д. Меньше известно о сочиально-психологических, медико-сочиальных и экономических предпосылках МЛУ МБТ.

Цель. Мы стремились выявить групповые сочиильно-психологические и медико-экономические особенности пациентов с МЛУ и широкой лекарственной устойчивостью (ШЛУ) МБТ по сравнению с рандомизированной выборкой здоровых мужчин.

Методы. Мы использовали исторический, сочиологический и статистический методы: $t$-критерий разности средних и относительных величин, логистическую регрессию, темп роста относительно уровня одной из групп, принятого за 100\%. Для анализа данных была сформирована когорта пациентов ГБУ РО «ОКЦФП» среднего возраста - 42 мужчины с МЛУ или ШЛУ МБТ - и группа контроля-38 взрослых мужчин, жителей г.Ростова-на-Дону и Ростовской области. Интегративный предиктор МЛУ (ШЛУ) МБТ рассчитывался при помощи индекса потерь-приобретений (ИПП).

Результаты. Логистическая регрессионная модель МЛУ (ШЛУ) МБТ, построенная на основе сочиологических данных, включала следующие свойства пациентов, значимо отличающие их от здоровых участников опроса: пол - мужчины наиболее уязвимы для МБТ с МЛУ (ШЛУ); при сравнении 
однопольх групп различались следующие индикаторы: «Я не могу ладить с людьми» - $(O R=6.33,95 \%, C I=1.35,29.7) ;$ " "Добиться порядка в нашей стране можно только с помощью грубой силы и жестокого наказания (я «за» смертную казнь)»- $(O R=10.86,95 \%, C I=1.35,87.49)$; «Вспоминаю о своем здоровье только при появлении каких-либо симптомов» $-(O R=$ $3.17,95 \%, C I=1.29,7.79) ;$ «Я информирован обо всех рисках для моего здоровья в полном объеме от врачей» - $(O R=2.35,95 \%, C I=1.00,5.51)$; «Врачи наметили конкретный план по снижению рисков для моего здоровья» - $(O R=3.92,95 \%, C I=1.46,10.55) ;$ «Я активно противодействию факторам риска, но не достигаю положительного результата» $-(O R=$ $8.14,95 \%, C I=1.77,37.43)$; «Имею вредные привычки, но консультируюсь у врачей по поводу своего текущего состояния» $-(\mathrm{OR}=5.88,95 \%, \mathrm{CI}=$ $1.88,18.4)$; «У меня нет никакой стратегии -живу, как живется» $-(O R=$ 3.02, 95\%, CI =1.10, 8.30); «У меня нет четких планов, не представляю свое будущее отчетливо»-(OR $=10.00,95 \%, C I=2.1,47.51)$.

Заключение. Полученные данные свидетельствуют о том, что пациенты 1-й группы проявляют озлобленность (высокую агрессивность), им свойственно одиночество, инфантильность, низкая соииальная востребованность, что лишает их возможности вести социально и экономически продуктивную жизнь (групповой индекс потерь-приобретений находится в зоне отрицательных значений). Полученные данные были использованы для разработки информационно-когнитивной программы сопровождения основного лечебного прочесса.

Ключевые слова: пациенты с множественной лекарственной устойчивостью; тусоваcterium tuberculosis; групповые сочиально-психологические особенности; медицинская эффективность; информационное сопровождение лечебного проиесса; индекс потерь-приобретений.

\section{SOCIO-PSYCHOLOGICAL FEATURES OF PULMONARY MDR/XDR TB MALE PATIENTS (COMPARISON WITH A RANDOMIZED SAMPLE OF HEALTHY MEN)}

\section{Chubaryan V.T., Saenko G.I., Khudonogov I.Yu., Modebadze E.V.}

Rationale. Studies of the clinical efficacy of various medical technologies used in the emergence of MDR/XDR Mycobacterium Tuberculosis (MBT) have 
been conducted quite often in recent decades. However, to a large extent, they are focused on the safety of new treatment regimens, on molecular genetic diagnostic methods, on the development of technological platforms for creating innovative anti-TB drugs, etc. Less is known about the socio-psychological, medico-social and economic background of MDR appearance.

Objective. We sought to identify the group socio-psychological characteristics of MDR/XDR TB male patients compared with a randomized sample of healthy men. Next, we examined the socio-economic predictors of MDR/XDR appearance.

Methods. We used historical, sociological and statistical methods: t-test, logistic regression, growth rate relative to the level of one of the groups, taken as $100 \%$. To analyze the data, a cohort of adult RCPC patients was formed-42 men with MDR or XDR MBT - and a control group - 38 adult men, residents of Rostov-on-Don and the Rostov Region. The MDR/XDR MBT Integrative Predictor was calculated using the loss-acquisition index (LAI).

Results. Logistic regression model of MDR (XDR) MBT, based on sociological data, included the following properties of patients, significantly distinguishing them from healthy participants in the survey: sex-men are most vulnerable to MBT with MDR (XDR); when comparing same-sex groups, the following indicators were distinguished: "I can't get along with people" $-(O R=6.33$, $95 \%, C I=1.35,29.7) ;$ "Order in our country can only be achieved through brute force and cruel punishment (I am for the death penalty)" - (OR $=10.86$, $95 \%, C I=1.35,87.49)$; "I remember about my health only when any symptoms appear" - $(O R=3.17,95 \%, C I=1.29,7.79)$; "I am fully informed of all risks to my health from doctors" - $(O R=2.35,95 \%, C I=1.00,5.51)$; "Doctors have outlined a specific plan to reduce the risks to my health" $-(O R=3.92,95 \%$, $C I=1.46,10.55)$; "I am actively opposing risk factors, but I am not achieved a positive result" - $(O R=8.14,95 \%, C I=1.77,37.43)$; "I have bad habits, but I consult with doctors about my current condition" $-(O R=5.88,95 \%, C I=$ $1.88,18.4)$; "I have no strategy - I live how I live" - $(O R=3.02,95 \%, C I=$ 1.10, 8.30); "I do not have concrete plans, I can't imagine my future clearly" $(O R=10.00,95 \%, C I=2.1,47.51)$

Conclusion. The data obtained indicate that patients of the 1st group show high aggressiveness, they are characterized by loneliness, infantilism, low social adaptation which deprives them of the opportunity to lead a socially and economically productive life (the group loss-acquisition index was in the negative values zone). The obtained data were used to develop an information and cognitive program to support the main treatment process. 
Keywords: $M D R / X D R T B$ male patients; group socio-psychological characteristics; medical effectiveness; information support of the treatment process; loss-acquisition index.

\section{Введение}

Российская Федерация и большинство стран постсоветского пространства вот уже скоро 30 лет характеризуются высокой долей туберкулеза с МЛУ (ШЛУ) mycobacterium tuberculosis (МБТ) [3] среди новых случаев туберкулеза и при рецидиве. Стоит также отметить, что удельный вес успешного лечения подобных больных в 2015 г. составил лишь 52\% и $28 \%$ для случаев с ШЛУ. Большинство авторов ожидают существенного повышения эффективности лечения больных туберкулезом с МЛУ и ШЛУ МБТ при условии использования новых препаратов, режимов лечения [4, 8] или хирургических пособий [7]. Однако движение фтизиатрической службы в указанном направлении как в Российской Федерации, так и за рубежом, сталкивается с проблемой роста случаев МЛУ (ШЛУ) МБТ на фоне снижения заболеваемости туберкулезом в целом [2]. При этом создается впечатление эпидемиологической неуправляемости патологического процесса, связанного с МЛУ (ШЛУ) МБТ. Иными словами, несмотря на повышенное внимание грантовой системы финансирования к тем направлениям медицинской науки, которые изучают возбудителя, слабые места его генома, особенности патогенных свойств, разрабатывают новые антибиотики и проч., МБТ адаптируется к инновационной деятельности фармацевтических компаний и приводит к летальному исходу все большего числа пациентов. Очевиден тот факт, что незаслуженно игнорируется информационное пространство, характеризующее именно фтизиатрических пациентов, особенно с МЛУ (ШЛУ) МБТ, которые, согласно нашей гипотезе, являются не только скоплением лейкоцитов, эритроцитов и иных клеток (т.е. биомассой), но существами мыслящими, находящимися в социуме, связь с которым у них проявляется весьма специфически, что и определяет тяжесть клинических проявлений. То есть, сущность их заболевания состоит не в конфликте, между МБТ и иммунной системой организма, хотя именно через них она опосредуется, но это лишь видимая часть айсберга, а истинный конфликт разворачивается между пациентом и социумом, но не в формате социопатии [6], а в форме психосоматики [5], активно влияющей и на инфекционную патологию. Особенно наглядно это конфликт проявляется в ситуации, когда возбудителя изначально вообще нет. Так, по данным Аксеновой В.А. и соавт. (2018) до 40\% детей, заболевших туберку- 
лезом с МЛУ МБТ, не имели контакта с массивным бактериовыделением, а являлись представителями «очага смерти» [1], т.е. такого микросоциального образования, в котором предполагаемый источник инфекции прекратил своё существование как физический объект до рождения ребенка, однако передал ему некоторые биохимические, морфофункциональные и информационно-когнитивные особенности, приведшие к МЛУ МБТ.

Вышесказанное определило цель нашего исследования: выявить групповые социально-психологические и медико-экономические особенности пациентов с МЛУ и ШЛУ МБТ по сравнению с рандомизированной выборкой здоровых мужчин.

Достижение указанной цели предполагало постановку следующих задач: разработка и апробация социологического инструментария, адаптированного для измерения способности вести социально и экономически продуктивную жизнь в среде пациентов с МЛУ (ШЛУ) МБТ; определение величины и полярности индекса потерь-приобретений [13] и основных групповых социально-психологических особенностей пациентов с МЛУ (ШЛУ) МБТ по отношению к группе контроля; измерить значимость выявленных особенностей; дать интерпретацию полученных данных с учетом необходимости построения глобальной профилактической среды и модернизации основного лечебного процесса за счет внедрения программ информационно-когнитивного сопровождения.

\section{Материалы и методы}

Авторами проведен сравнительный анализ данных, полученных в ходе социологического опроса. Исследовательский инструментарий - аннотация, информированное согласие и анкета были рассмотрены в Локальном независимом этическом комитете Федерального государственного бюджетного образовательного учреждения высшего образования «Ростовский государственный медицинский университет» Минздрава России (Выписка из протокола №13 от 13.09.2012 г.), одобрены и рекомендованы к применению экспертами Федерального института промышленной собственности (Свидетельство от 09.01.2018 г. № 2018620001 о регистрации в Едином реестре российских программ для электронных вычислительных машин и баз данных) [10]. Выборка пациентов ГБУ РО «ОКЦФП», страдающих от туберкулеза легких с МЛУ и ШЛУ МБТ, была сформирована из 42 добровольцев - взрослых мужчин (группа 1). Группа 2 была представлена рандомизированной выборкой здоровых мужчин (38 человек) - жителей г. Ростова-на-Дону и Ростовской области, с их информированного согласия 
на обработку персональных данных, полученного до начала исследования, которое проводилось в мае-июле 2018 года. Все участники опроса из группы №1 были представлены повторно госпитализированными больными с хроническим течением туберкулезного процесса. Все пациенты относились к группе диспансерного учета $2 \mathrm{~A}$. На предмет наличия значимой разницы было проанализировано 60 медико-социальных признаков. При сравнении большая часть из них, включая «возраст» $(42,7 \pm 1,5$ лет для 1-й группы и $39,9 \pm 1,7$ - для второй), оказалась не значима. Особое внимание было уделено верификации данных, характеризующих групповой индекс потерь-приобретений (ИПП) социально значимых объектов (СЗО) [9], который напрямую корреспондирует к завершающей части Преамбулы ВОЗ (1948), в которой сказано, что здоровье - это не только отсутствие болезней и физических дефектов, состояние полного физического, духовного и социального благополучия, но также способность вести социально и экономически продуктивную жизнь [14].

По данным кросс-секционного исследования рассчитывались средние и относительные величины для каждой группы, соответствующие ошибки репрезентативности, критерий Стьюдента для разности средних и относительных величин, а также относительный риск (относительная вероятность) проявления исследованных признаков - odds ratio (OR) - и доверительный интервал - confidence interval (CI) [17]. Обработка первичного материала выполнялась с помощью статистического программного продукта STATISTICA 13.5.0.17.msi (код продукта: 5ecfe967-5ec3-48b3b7ff-fa08b194d6b3). Результаты вычислений, вероятность ошибки которых превышала критическую величину $(\mathrm{p}=0,05)$, рассматривались как подтверждение нулевой гипотезы об отсутствии значимых различий.

\section{Результаты исследования}

В ходе статистического изучения степени социальной адаптации было показано, что количество респондентов, считающих себя «абсолютно» одинокими, в 1-й и 2-й группах являлось примерно одинаковым (по 20\%), также, как и число способных идти на компромисс (по 40\%). Тем не менее, доля тех, кто не может «ладить с людьми» (табл. 1) среди больных оказалось в 6,3 раза больше, чем среди здоровых и составила $33 \%$. Эта разница была значима с 95-процентным уровнем доверия (УД). Респондентов, «не мыслящих свою жизнь без общения», в группе 1 было в 2 раза меньше, однако УД составил лишь $72 \%$, что оказалось недостаточным для признания разницы статистически значимой. 
Таблицุа 1.

\section{Социально-психологические особенности групп по основным индикаторным направлениям}

\begin{tabular}{|c|c|c|}
\hline $\begin{array}{c}\text { Уровень приспособленности к жизни в обществе } \\
\text { (индикаторы социальной адаптации) }\end{array}$ & \begin{tabular}{c|} 
Odds \\
Ratio (OR)
\end{tabular} & $\begin{array}{l}\text { Confidence } \\
\text { Interval (CI) }\end{array}$ \\
\hline $\begin{array}{l}\text { 1. Я «волк-одиночка», стараюсь уединиться, обще- } \\
\text { ство мне неприятно, люблю простор и никаких лю- } \\
\text { дей вокруг (все попытки сблизиться с людьми закан- } \\
\text { чивались конфликтами). }\end{array}$ & 0.90 & $(0.31,2.65)$ \\
\hline 2. Я могу ладить с людьми, но делаю это не часто. & 6.33 & $(1.35,29.7)$ \\
\hline $\begin{array}{l}\text { 3. У меня есть и друзья и враги, но я способен идти } \\
\text { на компромисс. }\end{array}$ & 0.90 & $(0.41,1.99)$ \\
\hline $\begin{array}{l}\text { 4. В обществе мне очень комфортно, не представляю, } \\
\text { как бы я мог обходиться без него. } \\
\end{array}$ & 0.54 & $(0.18,1.64)$ \\
\hline \multicolumn{3}{|c|}{ Индикаторы нормативности социального поведения } \\
\hline $\begin{array}{l}\text { 1. Я игнорирую мнение общества, для меня не суще- } \\
\text { ствует никаких ограничителей, я всегда и все делаю } \\
\text { по своему разумению и не думаю о том, как это мо- } \\
\text { жет отразиться на других, или что они подумают. } \\
\end{array}$ & 0.36 & $(0.1,1.25)$ \\
\hline $\begin{array}{l}\text { 2. Я думаю, что морально-этические нормы в нашем } \\
\text { обществе нужны, но они слишком строгие, поэтому } \\
\text { иногда разрешаю себе их нарушать. }\end{array}$ & 1.21 & $(0.57,2.56)$ \\
\hline $\begin{array}{l}\text { 3. Даже когда меня никто не видит, я поступаю так, } \\
\text { как считается правильным в нашем обществе. } \\
\end{array}$ & 1.36 & $(0.5,3.68)$ \\
\hline Вероисповедание & OR & $\mathrm{CI}$ \\
\hline - православный; & 1.11 & $(0.56,2.19)$ \\
\hline - мусульманин; & 0.45 & $(0.08,2.61)$ \\
\hline - атеист; & 0.30 & $(0.06,1.59)$ \\
\hline - не знаю. & 3.62 & $(0.39,33.82)$ \\
\hline \multicolumn{3}{|c|}{ Указавшие вероисповедание уточнили степень своей религиозности: } \\
\hline 1 - просто симпатизируют указанной вере; & 0.66 & $(0.3,1.43)$ \\
\hline 2 - придерживаются основных канонов; & 0.90 & $(0.36,2.25)$ \\
\hline $\begin{array}{l}3 \text { - строго соблюдают все заповеди (являются орто- } \\
\text { доксами). }\end{array}$ & 2.71 & $(0.27,27.22)$ \\
\hline \multicolumn{3}{|c|}{ Индикаторы толерантности к смертной казни (уровень социальной зрелости) } \\
\hline $\begin{array}{l}\text { 1. Категорически против этого наказания, так как } \\
\text { оно отражает варварское антигуманное отношения к } \\
\text { личности. }\end{array}$ & 0.25 & $(0.09,0.67)$ \\
\hline $\begin{array}{l}\text { 2. Иногда возникает необходимость прибегать к } \\
\text { крайним мерам. }\end{array}$ & 1.55 & $(0.7,3.42)$ \\
\hline $\begin{array}{l}\text { 3. Добиться порядка в нашей стране можно только с } \\
\text { помощью грубой силы и жестокого наказания. }\end{array}$ & 10.86 & $(1.35,87.49)$ \\
\hline
\end{tabular}


В отношении индикаторов социальной зрелости респондентов [15], которые были применены в исследовании, можно утверждать, что достигли таковой лишь 13\% от пациентов с МЛУ (ШЛУ) МБТ. Значимые 4-11 кратные различия выявились при сравнении противоположных позиций почти $60 \%$ здоровых мужчин «за» гуманное отношение к преступникам, и столько же пациентов (группа 1) «против».

Социальная адаптация пациентов, по нашему мнению, и их социальная зрелость опосредуются коммуникацией, т.е. обменом социально значимой информацией между респондентами и представителями других социальных страт, в частности, с медицинскими работниками. Это тем более актуально, если учесть, что почти $80 \%$ опрошенных из 1-й группы практически не сталкиваются с объективной (некоммерческой) базовой медицинской информацией (табл. 2). Во 2-й группе таких было около 20\%.

Таблициа 2.

Характеристики и результативность медицинских коммуникаций в группах сравнения

\begin{tabular}{|l|c|c|}
\hline \multicolumn{1}{|c|}{ Индикаторы медицинской грамотности } & OR & СІ \\
\hline $\begin{array}{l}\text { 1. Имею медицинское образование, хорошо представляю } \\
\text { строение и функции своего организма. }\end{array}$ & 2.71 & $(0.52,14.27)$ \\
\hline $\begin{array}{l}\text { 2. Не медик, но читаю много медицинской литературы, } \\
\text { интересуюсь работой моего организма. }\end{array}$ & 0.18 & $(0.07,0.48)$ \\
\hline $\begin{array}{l}\text { 3. Вспоминаю о своем здоровье только при появлении } \\
\text { каких-либо симптомов. }\end{array}$ & 3.17 & $(1.29,7.79)$ \\
\hline $\begin{array}{l}\text { 4. Никогда не задумывался, как и что во мне происходит, } \\
\text { почему я болею. }\end{array}$ & 5.43 & $(0.62,47.17)$ \\
\hline \multicolumn{3}{|c|}{ Индикаторы актуальности медицинской информации } \\
\hline 1. Только об этом и думаю & 0.45 & $(0.15,1.32)$ \\
\hline $\begin{array}{l}\text { 2. Медицинская информация так же актуальна, } \\
\text { как и любая другая }\end{array}$ & 0.74 & $(0.35,1.59)$ \\
\hline 3. Мне это малоинтересно & 3.62 & $(0.39,33.82)$ \\
\hline \multicolumn{3}{|c|}{ Индикаторы информированности о рисках для здоровья } \\
\hline $\begin{array}{l}\text { 1. Я не представляю, что может угрожать } \\
\text { моему здоровью. }\end{array}$ & 0.09 & $(0.02,0.41)$ \\
\hline $\begin{array}{l}\text { 2. Наверняка какие-то риски есть, но никто } \\
\text { не информировал меня о них. }\end{array}$ & 0.54 & $(0.18,1.64)$ \\
\hline $\begin{array}{l}\text { 3. Врачи предупреждают о рисках вообще, но ничего } \\
\text { конкретного именно про меня не сообщают. }\end{array}$ & 2.26 & $(0.65,7.81)$ \\
\hline $\begin{array}{l}\text { 4. Я информирован обо всех рисках для моего здоровья } \\
\text { в полном объеме. Врач меня о них проинформировал. }\end{array}$ & 2.35 & $(1.00,5.51)$ \\
\hline
\end{tabular}


Окончание табл. 2.

Индикаторы наличия информации о минимизации рисков для здоровья

\begin{tabular}{|l|c|c|}
\hline 1. Никто и никогда не говорил мне об этом. & 0.27 & $(0.10,0.75)$ \\
\hline $\begin{array}{l}\text { 2. Некоторая информация у меня есть, но она не кажется } \\
\text { мне убедительной. }\end{array}$ & 0.45 & $(0.17,1.18)$ \\
\hline $\begin{array}{l}\text { 3. Врач наметил конкретный план, теперь я знаю, } \\
\text { как снизить риски, как избежать неблагоприятного } \\
\text { прогноза, как надо заниматься своим здоровьем. }\end{array}$ & 3.92 & $(1.46,10.55)$ \\
\hline
\end{tabular}

Результативность информационного сопровождения процесса минимизации рисков для здоровья и их коррекции

\begin{tabular}{|l|c|c|}
\hline $\begin{array}{l}\text { 1. Не знаю ни о каких факторах риска и не пытаюсь } \\
\text { ничего корректировать. }\end{array}$ & 0.15 & $(0.05,0.47)$ \\
\hline $\begin{array}{l}\text { 2. Я знаю все свои факторы риска, но не пытаюсь } \\
\text { с ними бороться. }\end{array}$ & 0.90 & $(0.31,2.65)$ \\
\hline $\begin{array}{l}\text { 3. Я активно противодействию факторам риска, } \\
\text { но редко достигают положительного результата. }\end{array}$ & 8.14 & $(1.77,37.43)$ \\
\hline $\begin{array}{l}\text { 4. Я отлично знаю все свои факторы риска и успешно } \\
\text { их регулирую. }\end{array}$ & 0.68 & $(0.22,2.13)$ \\
\hline
\end{tabular}

Значимо отличались такие индикаторы как «...читаю много медицинской литературы...» - пятикратное превышение группы здоровых, и «Вспоминаю о своем здоровье только при появлении каких-либо симптомов» - трехкратное превышение группы пациентов с МЛУ (ШЛУ) МБТ. При этом лишь 9\% группы 1 считают медицинскую информацию малоинтересной, что, однако почти в 4 раза больше, чем в группе 2 (УД=74\%).

Тем не менее, то информационное воздействие, которое оказывается на респондентов со стороны медицинских работников и носит предупредительный характер, признают более половины респондентов из группы 1 и отмечают, что информированы обо всех рисках для своего здоровья в полном объеме. Столько же представителей группы 2 «...не представляют, что может угрожать их здоровью...». Указанные различия являются значимыми и позволяют говорить об определенной запрограммированности происходящего, о существовании или отсутствии у различных людей негативных прогнозов (НП), т.е. пугающих образов будущего, в котором реализуются все риски.

Однако, если сам НП является деструктивной компонентой сознания, то меры профилактики, напротив, это позитивное и конструктивное начало в человеке. Так, 56\% пациентов с МЛУ (ШЛУ) МБТ, участвовавших в опросе, утверждали, что врачи наметили для них конкретный план по снижению рисков и вероятности наступления неблагоприятного прогноза, объяснили, как надо заниматься своим здоровьем. 
Респонденты из группы 1 почти в 4 раза чаще получают конкретные планы профилактики от врачей, и практически столько же представителей группы 2 подтверждают, что никто и никогда не занимался с ними медицинским планированием (УД=95\%). Оценивая медицинскую эффективность стандартных информационных воздействий со стороны врачей, больные туберкулезом с МЛУ и ШЛУ МБТ заключают почти в половине случаев, что активное противодействие факторам риска редко достигает положительного результата. Об успешном регулировании факторов риска заявили лишь 9\% респондентов. Более $40 \%$ больных утверждают, что «... активно противодействуют факторам риска, но редко достигают положительного результата...». Подтверждающих это высказывание респондентов из 2-й группы было в 8 раз меньше (УД=95\%).

Одной из важнейших причин низкой медицинской эффективности (НМЭ) коммуникации врачей и пациентов является высокая инфантильность (низкая социальная зрелость) последних, отсутствие у них навыков стратегического планирования и смысла самосохранения как такового. Респонденты 1-й группы почти в 70\% случаев делегируют полномочия по регулированию своего здоровья внешнему субъекту, т.е. врачу. Здоровые мужчины (группа 2) в 47\% случаев ведут здоровый образ жизни (ЗОЖ) и часто консультируются у врачей, что в 3 раза выше, чем в группе 1 , в $42 \%$ случаев ведут ЗОЖ без врачебных консультаций, что почти в 17 раз выше, чем в 1-й группе, и в 4-6 раз реже упоминают о вредных привычках на фоне отсутствия и наличия консультаций врача соответственно (табл. 3).

Таблииа 3.

Оценка респондентами основных элементов самосохранительного поведения

\begin{tabular}{|l|c|c|}
\hline \multicolumn{1}{|c|}{ Индикаторы отношения к здоровью } & OR & СI \\
\hline $\begin{array}{l}\text { 1. Я веду здоровый образ жизни и часто консультируюсь } \\
\text { у врачей по поводу своего текущего состояния }\end{array}$ & 0.30 & $(0.11,0.84)$ \\
\hline $\begin{array}{l}\text { 2. Я веду здоровый образ жизни, но не провожу } \\
\text { консультаций с врачами }\end{array}$ & 0.06 & $(0.01,0.45)$ \\
\hline $\begin{array}{l}\text { 3. Имею вредные привычки, но консультируюсь у врачей } \\
\text { по поводу своего текущего состояния }\end{array}$ & 5.88 & $(1.88,18.4)$ \\
\hline $\begin{array}{l}\text { 4. Имею вредные привычки и не консультируюсь у врачей } \\
\text { по поводу своего текущего состояния }\end{array}$ & 4.52 & $(0.93,21.97)$ \\
\hline \multicolumn{2}{|c|}{ Индикаторы отношения к медицинской коммуникации } \\
(нужно ли обращаться к врачу при отсутстии признаков заболевания?) \\
\hline 1. Конечно, нет. Это пустая трата моего времени & 0.06 & $(0.01,0.52)$ \\
\hline $\begin{array}{l}\text { 2. Здоровье надо проверять, но инициатива должна } \\
\text { исходить от самого человека }\end{array}$ & 1.11 & $(0.52,2.37)$ \\
\hline
\end{tabular}


Окончание табл. 3.

\begin{tabular}{|l|c|c|}
\hline $\begin{array}{l}\text { 3. Государство и работодатели заинтересованы } \\
\text { в здоровых работниках, пусть они все организовывают } \\
\text { и оплачивают, а мне все равно }\end{array}$ & 0.90 & $(0.05,14.97)$ \\
\hline $\begin{array}{l}\text { 4. Конечно, нужно, ведь мы (пациенты) много } \\
\text { не замечаем в своем организме, часто не понимаем, что } \\
\text { с ним происходит. Только врачи могут определить ранние } \\
\text { признаки нашей болезни и своевременно их вылечить }\end{array}$ & 2.49 & $(0.99,6.25)$ \\
\hline \multicolumn{1}{|c|}{ Индикаторы самосохранительной жизненной стратегии } \\
\hline $\begin{array}{l}\text { 1. Моя жизненная стратегия направлена на укрепление } \\
\text { здоровья и продление жизни }\end{array}$ & 0.81 & $(0.38,1.76)$ \\
\hline $\begin{array}{l}\text { 2. У меня есть более важные приоритеты, чем моё } \\
\text { здоровье }\end{array}$ & 0.30 & $(0.09,1.02)$ \\
\hline 3. У меня нет никакой стратегии - живу, как живется & 3.02 & $(1.10,8.30)$ \\
\hline
\end{tabular}

3. У меня нет никакой стратегии - Самооценка навыков планирования пациентов

1. Я имею четкие планы и достаточно отчетливо представляю свое будущее;

2. Я имею планы, но смогу ли я их реализовать зависит от многих факторов;

3. Разработка жизненных планов - это занятие бессмысленное и бесполезное.

$0.10(0.02,0.48)$

Оценка возможности саморегулирования продолжительности жизни пациентов

1. Жить надо долго, и все для этого делать.

2. Жить долго - это хорошо, но что-то для этого делать не входит в мои приоритеты.

3. Жизнь должна быть не столько продолжительной, сколько яркой и содержательной.

4. Жить надоело, я не вижу смысла в ее продлении

и целей дальнейшего существования.

\begin{tabular}{|c|c|}
\hline 0.45 & $(0.20,1.03)$ \\
\hline 2.41 & $(0.86,6.8)$ \\
\hline 0.90 & $(0.34,2.41)$ \\
\hline 7.24 & $(0.86,60.58)$ \\
\hline
\end{tabular}

Практически единодушно все участники опроса из 1-й группы заявили о наличии у них высокой потребности в обращении к врачу, о надежде на исцеляющую способность медицины и об инициативе, которая должна исходить именно от пациентов. Респонденты из 2-й группы в 37 случаях из 100 считают, что общение с врачом без наличия симптомов болезни - это пустая трата времени. Пациенты с МЛУ (ШЛУ) МБТ так думают в 16 раз реже (УД=95\%).

Другая причина НМЭ коммуникации врачей и пациентов кроется во врачах, точнее в том информационном профилактическом контенте (ИПК), который они транслируют. Чаще всего этот ИПК значительно фрагментирован и не содержит аксиологической составляющей, которую пациент мог бы использовать в качестве самосохранительной жизненной стратегией [12]. Более чем у половины больных с МЛУ (ШЛУ) МБТ нет никакой стратегии вообще, либо она не включает сохранение здоровья. В группе 2 таких респондентов значимо меньше в 3 раза. 
В контексте нашей работы слово «стратегия», имеющее латинский корень, который дословно обозначает «расслоение» чего-либо после перемешивания или встряхивания (паники, стресса), мы понимали как способность оценить обстановку спокойно, с учетом всех проявившихся тенденций, увидеть их перспективу, и если эта перспектива имеет негативную направленность разработать конкретный долгосрочный план достижения позитивной цели. Важной компонентой планирования является их реализация. Респонденты из группы 2 имеют по этому признаку 13 кратное превышение (УД=95\%).

По нашим данным почти $80 \%$ респондентов - пациентов с МЛУ (ШЛУ) МБТ - испытывают серьезные проблемы с реализацией своих самосохранительных планов. И основная причина этого - потеря смысла жизни, достойной цели существования, об отсутствии которой заявили почти $60 \%$ опрошенных пациентов с МЛУ (ШЛУ) МБТ, а полностью разочаровались в жизни и не видят смысла в ее продлении почти 20\% группы $1.63 \%$ здоровых мужчин (группа 2) задекларировали более, чем двукратное превышение по индикатору «Жить надо долго, и все для этого делать» (УД=94\%).

Глубинный смысл подобной психосоматики удалось открыть при помощи индикатора, количественно характеризующего потери и приобретения респондентами СЗО (табл. 4), которые были разделены на аффилиативные, связанные с личным общением, воспринимаемым как самоценность (близкие люди, родственники, трудовой коллектив, страна (родина)), и прагматические, опосредованные неодушевленными предметами и понятиями, имеющими высокую социальную значимость (работа, деньги, предметы длительного пользования). Так, оказалось, что аффилиативные потери группы 1 превышали таковые среди респондентов из группы 2 в 4 раза (УД=98\%), а прагматические - в 18 раз (УД=99\%). Относительно приобретений можно сказать, что они отличались незначимо ( $>0,05)$.

Таблицуа 4.

Социальная и экономическая продуктивность жизни респондентов в сравниваемых группах

\begin{tabular}{|l|c|c|}
\hline \multicolumn{1}{|c|}{ Потери социально-значимых объектов } & OR & CI \\
\hline Аффилиативные потери & 4.07 & $(1.27,13.1)$ \\
\hline Прагматические потери & 18.1 & $(2.32,141.37)$ \\
\hline Общие потери & 8.6 & $(2.8,26.34)$ \\
\hline \multicolumn{2}{|c|}{ Приобретения социально-значимых объектов } \\
\hline Аффилиативные приобретения & 0.53 & $(0.26,1.08)$ \\
\hline Прагматические приобретения & 4.52 & $(0.93,21.97)$ \\
\hline Приобретения в целом & 0.75 & $(0.39,1.45)$ \\
\hline
\end{tabular}


В пересчете на 1 участника опроса для 1-й группы ИПП составил «-0,19»; для группы $2-«+0,84 »$.

\section{Заключение}

Разработанная нами индикаторная система позволила установить, что нормальным уровнем социальной и экономической продуктивности (УСЭП) мужчин молодого (18-44 лет) и среднего возраста (45-59 лет по критериям ВОЗ) является уровень, соответствующий значению ИПП=+0,84. Респонденты 1-й группы (пациенты с МЛУ и ШЛУ МБТ) задекларировали УСЭП, соответствующий групповому ИПП=-0,19. Значимость разницы УСЭП определялась 4-кратным превышением аффилиативных потерь (УД=98\%) и 18-кратным превышением прагматических потерь группы 1 (УД=99\%) по сравнению с респондентами из группы 2.

Определяющую роль в снижении УСЭП играли следующие социально-психологические предикторы: низкий уровень социальной адаптации, одиночество, инфантильность, высокая нормативность социального поведения участников опроса из 1-й группы. Значимость выявленных особенностей была достаточной для опровержения нулевой гипотезы $(\mathrm{p}<0,05)$, утверждающей, что группы идентичны. Интерпретация полученных данных дала методические основания для модернизации основного лечебного процесса за счет внедрения программы информационно-когнитивного сопровождения, направленного на смещение полярности ИПП в область положительных значений у больных туберкулезом МЛУ и ШЛУ МБТ. Заметный с биологической точки зрения позитивный результат лечения возможен в условиях более широкого использования детализированной медицинской информации [16], расширения сферы коммуникации и включения в нее новых социально значимых объектов [11] в рамках занятий Школы здоровья. С учетом необходимости построения глобальной профилактической среды, полученные данные целесообразно использовать на ранних этапах развития специфических патологических процессов с целью усиления контроля над ними, либо до их наступления, т.е. при первых признаках снижения величины ИПП.

\section{Список литературы}

1. Аксенова В.А., Клевно Н.И., Кавтарашвили С.М., Казаков А.В., Пахлавонова А.Д. Очаг туберкулезной инфекции как риск развития туберкулеза у детей с множественной лекарственной устойчивостью возбудителя // Туберкулёз и болезни лёгких. 2018. Т. 96, № 1. С. 11-17. 
2. Борзенко А.С., Калуженина А.А., Шмелёв Э.Н., Шмелёв Э.Н., Попкова Н.Л., Гагарина С.Г., Таипов И.М., Юдин С.А. Новые режимы в терапии туберкулеза с множественной лекарственной устойчивостью // Аллергология и иммунология. 2013. Т. 14. № 1. С. 45.

3. Ванькович А.А., Ромащенко Е.И. Анализ эпидемических показателей по туберкулезу в Республике Беларусь и странах ближнего зарубежья // Актуальные проблемы современной медицины и фармации - 2017: Сборник материалов LXXI Международной научно-практической конференции студентов и молодых учёных. Белорусский государственный медицинский университет. 2017. С. 1433-1437.

4. Васильева И.А., Белиловский Е.М., Борисов С.Е., Стерликов С.А. Туберкулез с множественной лекарственной устойчивостью возбудителя в странах мира и в Российской Федерации // Туберкулез и болезни легких. 2017. Т. 95. № 11. С. 5-18.

5. Гундаров И.А., Полесский В.А. Профилактическая медицина на рубеже веков. От факторов риска - к резервам здоровья и социальной профилактике. Москва, 2016. 256 с.

6. Коновалова Л.Е. Социопатия // Закон и общество: история, проблемы, перспективы материалы XIX межвузовской студенческой научно-практической конференции (с международным участием). 2016. С. 327-328.

7. Разаков О.Р., Батиров Р.Р., Гаипов Р.Г., Юсупов Ж.Н., Абдиев М.Д. Роль имплантируемой порт системы для центрального венозного доступа в лечении туберкулёза лёгких с множественной и широкой лекарственной устойчивостью (предварительные результаты) // Вестник Авиценны. 2018. T. 20. № 2-3. С. 271-275.

8. Тихонов А.М., Буракова М.В., Ваниев Э.В., Романов В.В., Васильева И.А. Эффективность химиотерапии с применением бедаквилина у больных туберкулезом легких с лекарственной устойчивостью возбудителя // Туберкулез и болезни легких. 2018. Т. 96. № 2. С. 22-26.

9. Худоногов И.Ю. Групповая мотивационная матрица как регулятор общественного здоровья (структурно-функциональный анализ) // Современные подходы к продвижению здоровья. Электронный ресурс (CD-Диск). 2016. С. 93-96.

10. Худоногов И.Ю. Определение (прогноз) уровня накопленной заболеваемости на основе оценки информационно-когнитивной компоненты здоровья // Программы для ЭВМ. Базы данных. Топологии интегральных микросхем. 2018. № 1. С. 1.

11. Худоногов И.Ю., Иванов А.С., Зарубинская Л.Г., Певнева М.В., Чумаян А.Д. Научное обоснование когнитивно-информационного протезирования 
(медико-социологический анализ естественной репарации самосохранительных мотивационных матриц) // В мире научных открытий. 2018. Т. 10. № 3. C. 41-61.

12. Худоногов И.Ю., Осадчук О.А. Медико-социальные предпосылки формирования различных типов жизненных стратегий // Общество и здоровье: современное состояние и тенденции развития Сборник статей. Под редакцией профессора Решетникова Андрея Вениаминовича. 2013. С. 322-328.

13. Чумаян А.Д., Худоногов И.Ю., Иванов А.С. Особенности факторов риска, выявленных на приеме у пациентов врача-стоматолога ортопеда. Dental Forum. 2018. № 4. C. 116-118.

14. Элланский Ю.Г., Пузин С.Н., Айдинов Г.В., Чернецкий О.Е., Фисенко В.Л., Пакус И.О., Баранец Л.А., Савина Е.М, Тлепцеришев Р.А., Меметов С.Я., Ходарев С.В., Приз Е.В., Лукьянова Н.Н. Тезисы лекций по дисциплине «Общественное здоровье и здравоохранение». Учебное пособие для преподавателей и студентов. Под ред. проф. Элланского Ю.Г. Ростов-на-Дону, 2005. 168 с.

15. Элланский Ю.Г., Худоногов И.Ю., Якименко Л.А., Тимченко А.С. Структурные характеристики социального возраста на фоне современных российских политико-экономических реалий // В мире научных открытий. 2015. № 2-1 (62). С. 639-653.

16. Элланский Ю.Г., Худоногов И.Ю., Данилевская Т.В. Структурированность представлений о строении и функциях человеческого организма как инструмент управления общественным здоровьем // В мире научных открытий. 2016. № 3 (75). С. 85-100.

17. Select Statistical Services Ltd. Oxygen House, Grenadier Road, Exeter Business Park, Exeter, UK, «On-line Calculators». URL: https://select-statistics.co.uk/ calculators/ (дата обращения: 12.08.2019).

\section{References}

1. Aksenova V.A., Klevno N.I., Kavtarashvili S.M., Kazakov A.V., Pakhlavonova A.D. Tuberkulez i bolezni legkikh. 2018. V. 96, № 1. P. 11-17.

2. Borzenko A.S., Kaluzhenina A.A., Shmelev E.N., Shmelev E.N., Popkova N.L., Gagarina S.G., Taipov I.M., Yudin S.A. Allergologiya i immunologiya. 2013. V. 14. № 1. P. 45.

3. Van'kovich A.A., Romashchenko E.I. Aktual'nye problemy sovremennoy meditsiny i farmatsii - 2017 Sbornik materialov LXXI Mezhdunarodnoy nauchno-prakticheskoy konferentsii studentov $i$ molodykh uchenykh. Belorusskiy gosudarstvennyy meditsinskiy universitet [Actual problems of modern medi- 
cine and pharmacy - 2017 Collection of materials LXXI International scientific and practical conference of students and young scientists]. 2017. P. 1433-1437.

4. Vasil'eva I.A., Belilovskiy E.M., Borisov S.E., Sterlikov S.A. Tuberkulez $i$ bolezni legkikh. 2017. V. 95. № 11. P. 5-18.

5. Gundarov I.A., Polesskiy V.A. Profilakticheskaya meditsina na rubezhe vekov. Ot faktorov riska - $k$ rezervam zdorov'ya i sotsial'noy profilaktike [Preventive medicine at the turn of the century. From risk factors to health reserves and social prevention]. Moskva, 2016. 256 p.

6. Konovalova L.E. Zakon i obshchestvo: istoriya, problemy, perspektivy materialy XIX mezhvuzovskoy studencheskoy nauchno-prakticheskoy konferentsii (s mezhdunarodnym uchastiem) [Law and society: history, problems, prospects. Materials of the XIX inter-university student scientific-practical conference (with international participation)]. 2016. P. 327-328.

7. Razakov O.R., Batirov R.R., Gaipov R.G., Yusupov Zh.N., Abdiev M.D. Vestnik Avitsenny. 2018. V. 20. № 2-3. P. 271-275.

8. Tikhonov A.M., Burakova M.V., Vaniev E.V., Romanov V.V., Vasil'eva I.A. Tuberkulez i bolezni legkikh. 2018. V. 96. № 2. P. 22-26.

9. Khudonogov I.Yu. Sovremennye podkhody k prodvizheniyu zdorov'ya [Modern approaches to promoting health]. 2016. P. 93-96.

10. Khudonogov I.Yu. Programmy dlya EVM. Bazy dannykh. Topologii integral'nykh mikroskhem. 2018. № 1. P. 1.

11. Khudonogov I.Yu., Ivanov A.S., Zarubinskaya L.G., Pevneva M.V., Chumayan A.D. V mire nauchnykh otkrytiy. 2018. V. 10. № 3. P. 41-61.

12. Khudonogov I.Yu., Osadchuk O.A. Obshchestvo $i$ zdorov'e: sovremennoe sostoyanie i tendentsii razvitiya. Sbornik statey [Society and Health: Current Status and Development Trends. Collection of articles]. Ed. Reshetnikov Andrey Veniaminovich. 2013. P. 322-328.

13. Chumayan A.D., Khudonogov I.Yu., Ivanov A.S. Dental Forum. 2018. № 4. P. $116-118$.

14. Ellanskiy Yu.G., Puzin S.N., Aydinov G.V., Chernetskiy O.E., Fisenko V.L., Pakus I.O., Baranets L.A., Savina E.M, Tleptserishev R.A., Memetov S.Ya., Khodarev S.V., Priz E.V., Luk'yanova N.N. Tezisy lektsiy po distsipline «Obshchestvennoe zdorov'e i zdravookhranenie» [Theses of lectures on the discipline "Public Health and Health Care"]. ed. Ellansky Yu.G. Rostov-na-Donu, 2005. 168 p.

15. Ellanskiy Yu.G., Khudonogov I.Yu., Yakimenko L.A., Timchenko A.S. V mire nauchnykh otkrytiy. 2015. № 2-1 (62). P. 639-653.

16. Ellanskiy Yu.G., Khudonogov I.Yu., Danilevskaya T.V. V mire nauchnykh otkrytiy. 2016. № 3 (75). P. 85-100. 
17. Select Statistical Services Ltd. Oxygen House, Grenadier Road, Exeter Business Park, Exeter, UK, «On-line Calculators». https://select-statistics.co.uk/calculators/

\section{ДАННЫЕ ОБ АВТОРАХ}

Чубарян Вартан Тарасович, доктор медицинских наук, профессор, заведующий кафедрой фтизиатрии и пульмонологии ФПК и ППС ФГБОУ ВО РостГМУ Минздрава России пер. Нахичеванский, 29, 344022, г. Ростов-на-Дону, Российская Федерация chubar88@yandex.ru

Саенко Галина Ивановна, доктор медицинских наук, врач-фтизиатр высшей категории, главный врач ГБУ РО «ОКЦФП» ул. Орская, 24, г. Ростов-на-Дону, 344065, Российская Федерация gotsakh35@mail.ru

Худоногов Игорь Юрьевич, кандидат медицинских наук, старший преподаватель кафедры общественного здоровья и здравоохранения №1 с курсом истории медицины ФГБОУ ВО РостГМУ Минздрава России пер. Нахичеванский, 29, 344022, г. Ростов-на-Дону, Российская Федерачия fux1@yandex.ru

Модебадзе Екатерина Владимировна, с-т лечебно-профилактического факультета, член молодежного научного общества кафедры общественного здоровья и здравоохранения №1 с курсом истории медицины ФГБОУ ВО РостГМУ Минздрава России пер. Нахичеванский, 29, 344022, г. Ростов-на-Дону, Российская Федерачия K_M1999@mail.ru

\section{DATA ABOUT THE AUTHORS}

Chubaryan Vartan Tarasovich, Doctor of Medical Sciences, Professor, Head of the Department of Phthisiology and Pulmonology, FPK and PPS Rostov State Medical University of the Ministry of Health of Russia 
29, Nakhichevan per., 344022, Rostov-on-Don, Russian Federation chubar88@yandex.ru

Saenko Galina Ivanovna, Doctor of Medical Sciences, Phthisiatrist of the highest category, head physician Regional Clinical Center of Phthisiopulmonology 24, Orskaya st., Rostov-on-Don, 344065, Russian Federation gotsakh35@mail.ru

Khudonogov Igor Yuryevich, Candidate of Medical Sciences, Senior Lecturer, Department of Public Health and Healthcare №1 with a history of medicine Rostov State Medical University of the Ministry of Health of Russia 29, Nakhichevan per., 344022, Rostov-on-Don, Russian Federation fux1@yandex.ru SPIN-code: 8063-0786 ORCID ID: 0000-0003-1879-012X ResearcherID: B-4399-2016

Modebadze Ekaterina Vladimirovna, Faculty of Medicine and Prevention, member of the Youth Scientific Society of the Department of Public Health and Healthcare №1 with a history of medicine Rostov State Medical University of the Ministry of Health of Russia 29, Nakhichevan per., 344022, Rostov-on-Don, Russian Federation K_M1999@mail.ru 